\title{
CONTRIBUTIONS OF ANAEROBIC METABOLISM TO pH REGULATION IN ANIMAL TISSUES: THEORY
}

\author{
BY HANS-OTTO PÖRTNER
}

Institut für Zoologie IV, Universität Düsseldorf, D-4000 Düsseldonf, IRRG*, Abteilung Physiologie, Max Planck Institut für experimentelle Medizin, D-3400 (Göttingen, FRG and Department of Biology, Acadia Lniversity, Wolfille, Noza Scotia, Canada BOP 1 YO

Accepted I May 1987

\section{SUMMARY}

Proton balance is analysed in relation to the anaerobic and aerobic metabolism of carbohydrates, carbonic acids, amino acids and fat by considering oxidation, carboxylation, decarboxylation and phosphorylation reactions, as well as the influence of ammonium, on the acid-base status of animal tissues. The functional role of the adenylates, phosphagens and inorganic phosphate in acid-base balance is investigated with respect to differences in the physicochemical properties of organic and inorganic phosphates.

General principles are established for different anaerobic metabolic pathways in species from several phyla. It is concluded that proton release from the substrate, which is always involved in substrate-level phosphorylations, is essential for the mechanism of ATP formation. Anaerobic metabolism, which is characterized by incomplete oxidation of carbon chains and an accumulation of acidic groups, supports $\mathrm{pH}$ regulation in facultative anaerobes by minimizing the amount of accumulated protons. High levels of phosphagens mean high proton absorption during hydrolysis and an increase in the intracellular buffer value. Decarboxylation reactions in catabolic pathways are equivalent to proton consumption. The degradation of carbonic acids during anaerobiosis, therefore, contributes to $\mathrm{pH}$ regulation. Release of ammonia or ammonium ions in catabolism is also linked to the buffering of protons originating from the formation of carboxyl groups and net cleavage of ATP. Net disposal of amino groups or ammonium ions by transamination, reductive amination or ion exchange does not change this general picture. The proton, bicarbonate and $\mathrm{CO}_{2}$ turnover in metabolic pathways is discussed with respect to the interrelationships between $\mathrm{pH}$ and metabolic regulation.

\section{INTRODUCTION}

Anaerobic metabolic pathways are believed to cause $\mathrm{pH}$ changes in animal tissues. Tissue $\mathrm{pH}$, however, is one of the most decisive modulators of enzyme function and is important for energy transductions. Its regulation is essential not only during

* Address for reprint requests.

Key words: anaerobic metabolism, aerobic metabolism, pH regulation, protons, ammonia, ammonium, deamidation, deamination, amination, transamination, phosphagen, phosphate, buffering, phosphorylation, ATP, ADP, AMP, IMP, adenosine, inosine, magnesium. 
aerobiosis but also during periods of restricted oxygen availability. Whereas most research in the field of acid-base regulation has focused on ionic transport mechanisms, it has only recently become evident that metabolism can also contribute to $\mathrm{pH}$ homeostasis (Atkinson \& Camien, 1982). By considering different mechanisms of anaerobic energy production among vertebrates and invertebrates, the present paper is intended to analyse the extent to which this holds true for anaerobic metabolism. In addition, the consideration of the participation of protons in metabolic reactions yields an insight into the interrelationships between the regulation of metabolism and of pH. Special emphasis is given to those animal species that are good anaerobes, in the sense that they are able to survive long periods of hypoxia. Mechanisms are presented in more detail for marine invertebrates, so that quantitative correlations can be made between anaerobic metabolic and acid-base events (Pörtner, 1987).

In the oxidative pathways of energy metabolism, three tightly coupled components take part in the reactions; the carbon chains of the substrates, the adenylates and the $\mathrm{NADH}+\mathrm{H}^{+} / \mathrm{NAD}^{+}\left(\mathrm{FADH}_{2} / \mathrm{FAD}\right)$ system. All components exhibit a specific turnover of protons in their respective conversions. Regulation of metabolism focuses on the maintenance of a constantly high energy status (simply expressed as a constant ATP/ADP $\times \mathrm{P}_{i}$ ratio at constant $\mathrm{pH}$ and $\mathrm{pMg}^{2+}$ ) and of the $\mathrm{NADH} /$ $\mathrm{NAD}^{+}$ratio, which are parameters that may be thought of as being general indicators of the metabolic state of a tissue (Erecinska \& Wilson, 1982). This principally means that, during aerobiosis or anaerobiosis, ATP synthesis by metabolism only occurs because ATP has been cleaved and NADH is only oxidized because NAD has been reduced. Resynthesis of ATP or reoxidation of NADH, however, may be delayed during anaerobiosis, starvation or transition to dormancy (Busa \& Nuccitelli, 1984), the delay being compensated for during return to 'normal' steady state. Such deviations from steady state will be considered at the end of this analysis. The general principles, however, are most easily understood when steady-state conditions are assumed in terms of constant ATP, ADP, $\mathrm{P}_{\mathrm{i}}, \mathrm{NADH}$ and $\mathrm{NAD}^{+}$, and $\mathrm{CO}_{2}$ and bicarbonate concentrations at constant $\mathrm{pH}$. Then no mistake is introduced by writing whole numbers in the equations (Figs 2, 4, 5,6) that select $\mathrm{MgATP}^{2-}, \mathrm{MgADP}^{-}$, $\mathrm{P}_{i}{ }^{2-}, \mathrm{H}^{+}$, and $\mathrm{CO}_{2}$ or bicarbonate as participants* (Pörtner, 1982; Pörtner, Heisler \& Grieshaber, 1984b). Whereas it is widely accepted that a constant NADH/NAD ${ }^{+}$ couple has no net influence on the proton balance of metabolism, the specific role of the adenylates must be briefly analysed. The role of $\mathrm{CO}_{2}$ and bicarbonate will be discussed with reference to the basic principles of acid-base physiology.

\section{PARTICIPATION OF THE ADENYLATES}

During the last few years, several authors have emphasized that the proton release during anaerobic lactate formation is not due to the dissociation of lactic acid but is linked to the metabolism of ATP (Gevers, 1977; Zilva, 1978; Hochachka \&

* It is very likely that only the $\mathrm{Mg}^{2+}$ complexes of the adenylates take part in the reaction, since nost, if not all, kinases need $\mathrm{Mg}^{2+}$ as a cofactor (see Dixon $\&$ Webb, 1979). 
Mommsen, 1983). This assumption is based on the fact that ATP synthesis is coupled to the energy-vielding oxidation of phosphoglyceraldehyde (see Figs 2, 5). The net process is the generation of a carboxyl group, which at cell $\mathrm{pH}$ releases a proton. However, a proton is absorbed when $\mathrm{MgADP}^{-}$is rephosphorylated. The carboxyl group remains unchanged during the further conversion towards lactate, whereas the proton absorbed during ADP phosphorylation would be released ria $\mathrm{MgATP}{ }^{2-}$ hydrolysis. In steady state, lactate and protons are the end-products. The chemical origin of the proton is undoubtedly the carboxyl group present in lactate. This point can be overlooked by the above-mentioned approach, but it always holds true even if the respective stoichiometry may secondarily appear to be influenced by net synthesis or cleavage of ATP (see below for non-steady-state conditions).

Modifications of anaerobic glycolysis, which are observed in facultatively anaerobic invertebrates such as marine bivalves, annelids and sipunculids, do not change this general picture. These animals form opines instead of lactate in the terminal reaction of the glycolytic pathway (Gäde \& Grieshaber, 1986):

$$
\text { pyrurate }{ }^{-}+\text {amino acid }+2 \mathrm{H} \rightarrow \text { opine }^{-} \text {. }
$$

Since these animals rely on pools of the different amino acids (alanine, glycine, arginine $^{+}$, taurine) needed for opine (alanopine ${ }^{-}$, strombine ${ }^{-}$, octopine, tauropine ${ }^{-}$) formation, the only net process is the production of pyruvate and $\mathrm{H}^{+}$in the Embden-Meyerhof pathway. The amino acids enter the reaction with practically unchanged $\mathrm{pK}^{\prime}$ values, i.e. all functional groups remain in the same state of protonation (even if it is arginine that is released during phospho-L-arginine hydrolysis and consumed during octopine formation, Fig. 1). Therefore, anaerobic glycolysis always leads to the accumulation of $1 \mathrm{~mol} \mathrm{H}^{+}$per mol of end-product formed (Pörtner, 1982; Pörtner et al. 1984b). The resulting proton load can be seen as a price for rapid stimulation of ATP synthesis during periods of high energy demand. End-products of glycolysis are rarely observed as the exclusive anaerobic end-products in good anaerobes. During hibernation, some turtles seem to rely on lactate and are able to minimize the acidosis during long periods of anaerobiosis by using their shell calcium carbonate as a buffer and by greatly reducing their metabolic rate at low temperature (Jackson, 1986).

Proton release by glycolysis, however, is often counteracted by proton consumption and inorganic phosphate release during phosphagen hydrolysis. The physicochemical properties of phosphocreatine and phospho-L-arginine were analysed early on (Meyerhof \& Lohmann, 1928) and can be generalized for any phosphagen (see Van Thoai \& Roche, 1964. A common element of a phosphagen is the guanidino group utilized as a binding site of phosphate). The net process during phosphagen depletion is the release of inorganic phosphate via ATP hydrolysis (at $\mathrm{pH} 7 \cdot 3$ ):

$$
\mathrm{R} \cdot \mathrm{PO}_{3}{ }^{2-}+\mathrm{H}_{2} \mathrm{O}+0 \cdot 24 \mathrm{H}^{+} \rightarrow \mathrm{R}-\mathrm{H}+0 \cdot 24 \mathrm{P}_{\mathrm{i}}^{-}+0 \cdot 76 \mathrm{P}^{2-} \text {. }
$$

The net uptake of protons is caused by a change in the $\mathrm{pK}^{\prime}$ of phosphate which, during phospho-L-arginine hydrolysis, for example, changes from 4.5 to 6.81 . 
pH 7.2

$$
\begin{gathered}
\text { Phospho-1-arginine } \\
\text { L-arginine } \\
=
\end{gathered}
$$

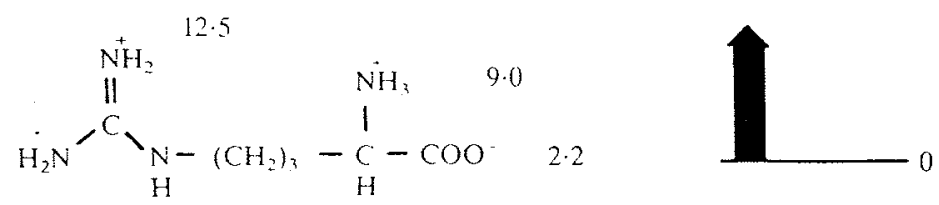

Octopine

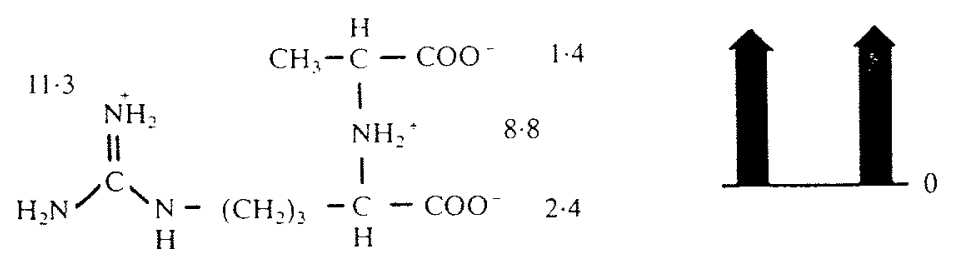

Fig. 1. Pattern of protonation and dissociation of phospho-L-arginine, L-arginine and octopine in the range of cell $\mathrm{pH}$. The stoichiometric relationship (indicated by the relative lengths of the arrows) between proton balance $\left(\Delta \mathrm{H}^{+}\right.$, assuming constant ATP concentrations) and anaerobic concentration changes $(\Delta C)$ results from the fact that dissociation constants of the $\mathrm{L}$-arginine residue (adopted from Sober, $1973 ; \mathrm{pK}$ values are given close to the respective functional groups) remain virtually unchanged in the different binding states. During phospho-L-arginine depletion, proton consumption is due to the release of inorganic phosphate. There is no proton release or consumption linked to L-arginine accumulation, whereas binding of the pyruvate residue during octopine formation reflects stoichiometric proton production (see text).

Phosphagen depletion, however, occurs mainly during the initial phases of anaerobiosis or muscular activity. Depending upon the amount of phosphagen and the rate of anaerobic metabolism, this may even lead to an alkalosis (see Pörtner, Grieshaber $\&$ Heisler, 1984a; Chih \& Ellington, 1985). Inorganic phosphate is then accumulated in the tissues and increases the amount of intracellular buffer substances (Pörtner et al. $1984 b$ ). Since intracellular $\mathrm{pH}$ under aerobic conditions is well above $\mathrm{pH}=7 \cdot 0$, a decrease of $\mathrm{pH}$ during anaerobiosis that does not proceed further than 6.8 automatically increases the $\mathrm{H}^{+}$buffering by accumulated phosphate originating from the net breakdown of phosphagen and of ATP. Phosphagens, whose concentrations are high in tissues with high glycolytic capacity, can therefore not only be seen as substances buffering changes in the ATP content, but also as a pool for potential 
proton buffering in the cell. This functional role is substantiated by the fact that, during recovery from anaerobiosis, rapid resynthesis of the phosphagen occurs (more rapid than the metabolism of accumulated acid anions). The protons buffered by inorganic phosphate during anaerobiosis are released, thereby transiently increasing the proton load of the organism. Efficient ion transfer to the extracellular or extracorporal medium (water, urine) during aerobiosis, however, is able to minimize the proton load of the intracellular compartment (Pörtner, Vogeler \& Grieshaber, $1986 a, b)$.

\section{OXIDATION, CARBOXYLATION AND DECARBOXYLATION REACTIONS}

During anaerobiosis in some animal tissues, mitochondria may be involved in the production of energy. Glycogen (or glucose), amino and/or dicarboxylic acids are known to be the substrates for this type of anaerobic metabolism. Succinate and ethanol (in goldfish and crucian carp; ethanol is also found in insect larvae, Wilps \& Zebe, 1976) are end-products found in vertebrate tissues (Hochachka, Owen, Allen \& Whittow, 1975; Sanborn et al. 1979; Taegtmeyer, 1978; Freminet, 1981; van den Thillart \& van Waarde, 1985). The end-products in marine invertebrates are highly varied. Alanine, succinate, propionate and acetate may be formed from glycogen or aspartate (Felbeck, 1980; Schöttler, 1980; Pörtner et al. 1984c).

The proton balance of these pathways cannot simply be explained by proton release ria ATP hydrolysis, since proton-relevant reactions, which do not directly include ATP synthesis, are involved. Other reactions deliver energy for ATP synthesis but do not affect the acid-base status. Fig. 2 shows the basic oxidation reactions involved in energy production during catabolism of fats, carbohydrates, proteins or amino acids. Oxidation involves the transformation of saturated into unsaturated substances, the formation of carbonyl groups from alcohols, and finally yields acidic carboxyl groups. During formation, however, these groups are esterified with coenzyme $\mathrm{A}$ or form an anhydride with inorganic phosphate, as in glycolysis.

The formation or consumption of carboxyl groups is also caused by carboxylation and decarboxylation reactions, respectively (Fig. 2). Decarboxylation occurs during oxidation (in the citric acid cycle, during oxidation of malate by malic enzyme) or is biotin-dependent (formation of propionate) and yields bicarbonate or $\mathrm{CO}_{2}$. Carboxylation, however, consumes bicarbonate or $\mathrm{CO}_{2}$ (carboxylation of phosphoenolpyruvate, pyruvate, acetyl-CoA). If bicarbonate takes part in the reaction (and this has been shown for biotin-dependent carboxylation or decarboxylation, Kaziro, Hass, Boyer \& Ochoa, 1962; Cooper, Tchen, Wood \& Benedict, 1968), decarboxylation can be seen as proton consumption. Bicarbonate may be transferred into $\mathrm{CO}_{2}$ and water by taking up protons, thereby physiologically acting as a base equivalent. Carboxylation can therefore be interpreted as proton release, since base equivalents are consumed. Decarboxylation and carboxylation, however, may also occur by release or fixation of $\mathrm{CO}_{2}$ (as in oxidative decarboxylation or phosphoenolpyruvate carboxykinase reactions, respectively, Hansl \& Waygood, 1952; Cooper et al. 1968). 
I<smiles>[3H]OCC(=O)[C@@H](O)[C@@H](S)C(C)C</smiles><smiles>O=C(S)C(O)CO[18F]</smiles>

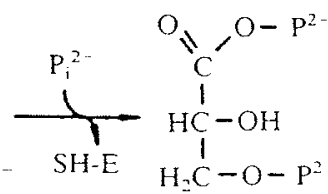

Glycolysis

II

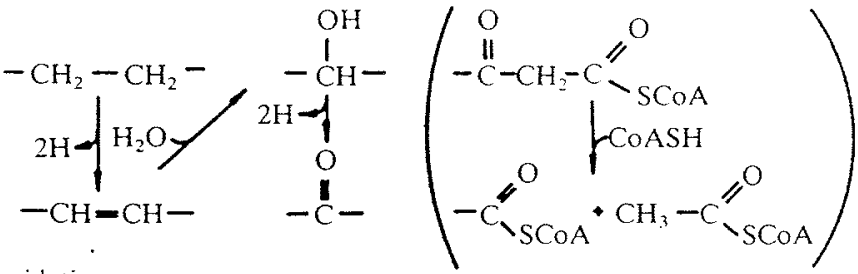

$\beta$-oxidation

III<smiles>CC(=O)SCCCCC(C)C(=O)C(C)C(=O)C(C)=O</smiles>

Oxidative decarboxylation of: pyruvate
$\alpha$-ketoglutarate

Reductive carboxylation of:

IV<smiles>CC(C(=O)[O-])C(=O)[O-]</smiles><smiles>COC(C)C(C)C(=O)[O-]</smiles><smiles>CCC(=O)SCCO</smiles>

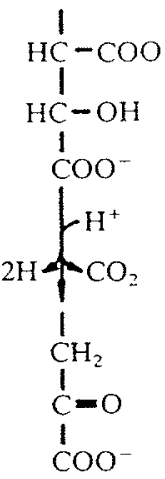

isocitrate

malate<smiles>CC(O)CC(=O)[O-]</smiles><smiles>CC(C)C(C)C(=O)[O-]</smiles>

$\mathrm{CH}_{3}$ $\stackrel{1}{\mathrm{HC}}=\mathrm{O}$ biotin-dependent

decarboxylation (of methyl-malonyl-CoA) and carboxylation (of propionate, pyruvate) biotin-COO${ }^{-}+\mathrm{MgADP}^{-}+\mathrm{P}_{1}^{2-}+\mathrm{H}^{+}+\mathrm{H}_{2} \mathrm{O} \rightleftharpoons$ biotin- $\mathrm{H}+\mathrm{HCO}_{3}^{-}+\mathrm{MgATP}^{2-}$

Fig. 2. Oxidation, carboxvlation and decarboxvlation reactions in the acrobic and anaerobic catabolism of carbon chains. Oxidation of carbonyl groups yields energy-rich esters or anhydrides of coenzyme A (CoASH) and phosphate $\left(\mathrm{P}_{\mathrm{i}}\right)$, respectively. 
This process is linked to a stoichiometric proton consumption or release, if the $\mathrm{CO}_{2}$ concentration is kept constant. $\mathrm{CO}_{2}$ and bicarbonate metabolism describes the link between respiratory and non-respiratory (also called metabolic) changes in the acid-base status. In this context it is useful to adopt some basic principles utilized in acid-base physiology, where volatile and non-volatile acids are distinguished. The carboxyl group of organic acids (predominantly non-volatile) may be transferred into the volatile acid $\mathrm{CO}_{2}$ by decarboxylation. Production of $\mathrm{CO}_{2}$ and its release by steady-state gas exchange means, for the most part, a reduction of the non-volatile acid load of the organism. Most carboxylation or decarboxylation reactions, which do not involve ATP as a mediator of proton release or consumption by the catabolism of carbon chains, are located inside the mitochondria (pyruvate, acetyl-CoA, propionyl-CoA formation, see Fig. 3, ethanol synthesis, see van den Thillart \& van Waarde, 1985). They are, however, most important for the proton balance of metabolism (Table 1). Neglecting this concept has led to the erroneous hypothesis that the proton stoichiometry during anoxia does not depend on the pathway utilized (Hochachka \& Mommsen, 1983). In fact, the yield of protons is very specific for the substrates involved and the end-products formed (Pörtner, 1982; Pörtner et al. 1984b; Table 1; for the reaction sequence in facultatively anaerobic invertebrates see Fig. 3).

In the lower invertebrates, short-chain fatty acids (e.g. acetate, propionate) are produced and released by the animals into the ambient water. These acids may be classified as being volatile with regard to their influence on the acid-base status, if their disposal occurs by non-ionic diffusion, thereby reducing the acid load of the organism. Evidence is still scarce, however, that these acids leave the organism in an undissociated form.

In our own recent analysis (Pörtner, 1982; Pörtner et al. 1984b), we have not considered the difference between the substrates $\mathrm{CO}_{2}$ and bicarbonate to be important in the proton balance of metabolism. If we distinguish between the two, we will gain a closer insight into the interrelationships between cellular acid-base and metabolic regulation. During anaerobiosis in marine invertebrates, phosphoenolpyruvate is carboxylated, finally yielding succinate and propionate (see Schöttler, 1980). The fact that phosphoenolpyruvate carboxykinase uses $\mathrm{CO}_{2}$ (see above) can be seen as advantageous, since hypoxic exposure in lower invertebrates is often linked to hypercapnia. The carboxylation involving $\mathrm{CO}_{2}$ may also be seen to be correlated with the low $\mathrm{pH}$ optimum of this enzyme. However, bicarbonate release during propionate synthesis under long-term hypoxia may be facilitated by the concomitant metabolic acidosis. Anaerobiosis can be expected to reduce mitochondrial $\mathrm{pH}$ by inhibition of the respiratory chain. Therefore, stimulation of propionate synthesis seems possible, since a low $\mathrm{pH}$ (at constant $\mathrm{P}_{\mathrm{CO}_{2}}$ ) means an automatic reduction in the bicarbonate concentration. This assumption is supported by the $\mathrm{pH}$ optimum of propionyl-CoA carboxylase being lower during decarboxylation than during carboxylation (Schulz, van Duin \& Zandee, 1983). These interrelationships, however, remain largely uninvestigated, as also is the interrelationship between $\mathrm{CO}_{2}$ release during ethanol synthesis and acid-base regulation in anoxic goldfish. 


\section{REDOX BALANCE AND PHOSPHORYLATION}

Reduction equivalents produced during oxidation ( $2 \mathrm{H}$, Figs 2,3 ) are reconsumed by pyruvate reductases, such as lactic or opine dehydrogenases, or by the reduction of unsaturated groups, a mechanism which is thought to involve mainly fumarate and unsaturated fatty acids (Fig. 4). In aerobic metabolism, reduction equivalents yield

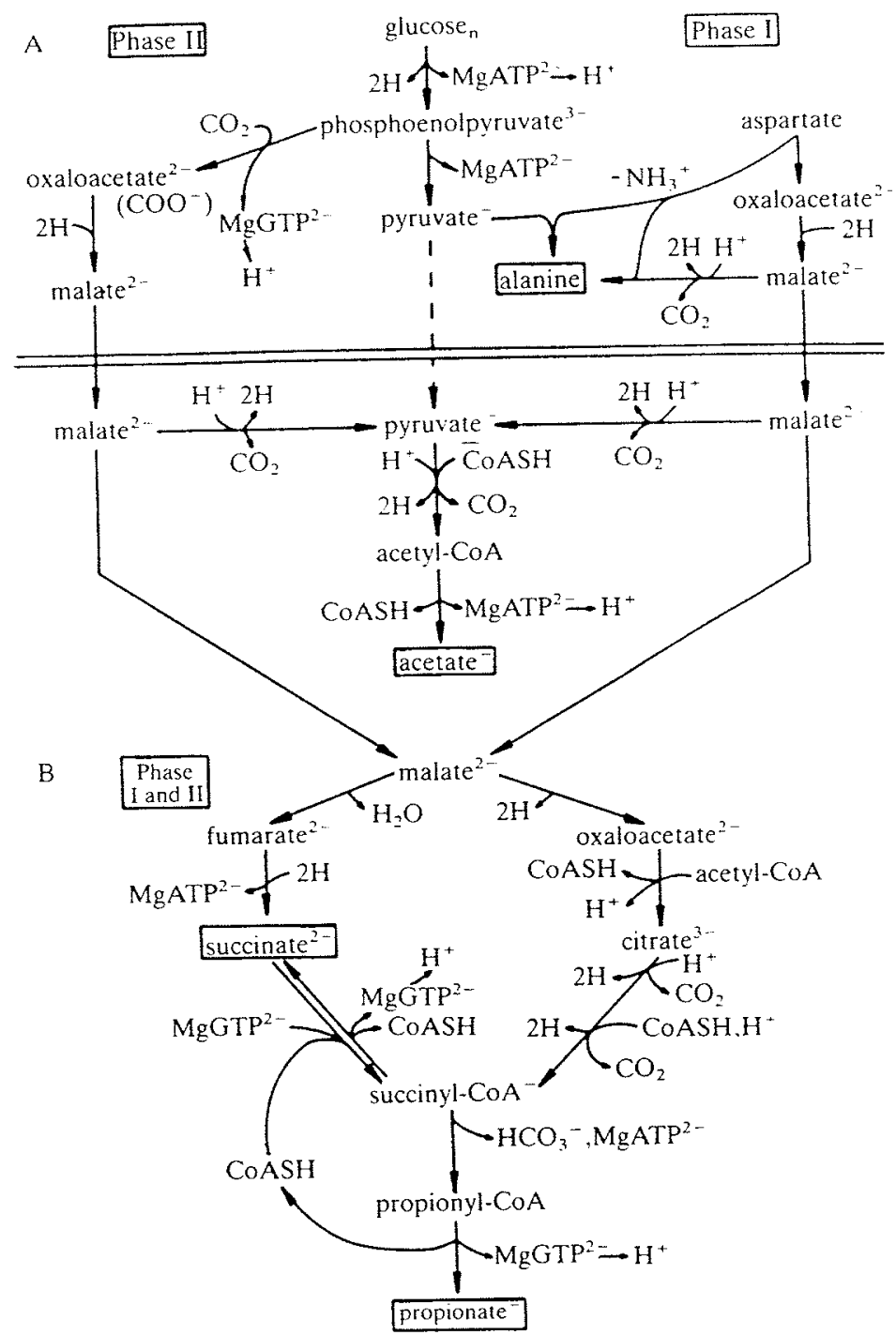

Fig. 3. Sequence of oxidation, carboxylation and decarboxylation reactions in the anaerobic catabolism of glycogen and aspartate in marine bivalves, annelids and sipunculids (modified after Pörtner, Heisler \& Grieshaber, 1984b). Phases I and II represent the early phase and the period of long-term anaerobiosis, respectively, $(A)$ in the cytosol and $(\dot{B})$ in the mitochondrion. $-\mathrm{COO}^{-}$indicates where carbosyl groups are formed de novo. MgNTP ${ }^{2-} \rightarrow \mathrm{H}^{+}$indicates where substrate-level phosphorylation is linked to the net release of protons. 
Consumption of reduction equivalents $(2 \mathrm{H})$ by:

pyruvate reductases

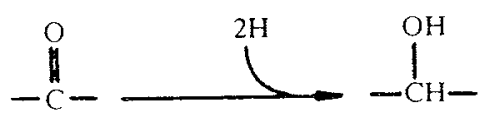

double bond reduction?

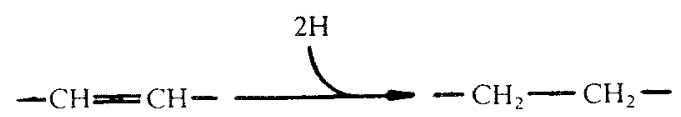

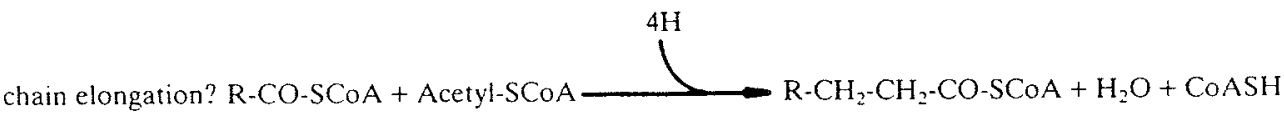

oxidative phosphorylation

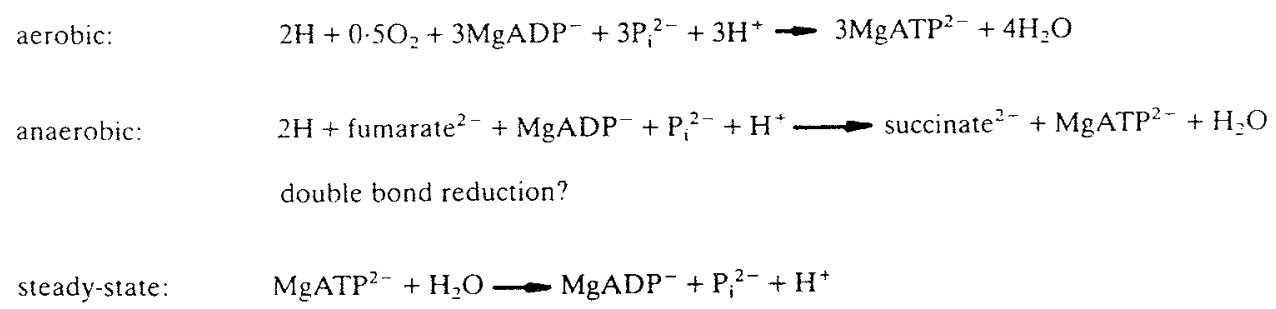

Oxidative phosphorylation: turnover of protons (not originating from the pathway) via ATP $\left(\Delta \mathrm{H}^{+}=0\right)$

Fig. 4. Consumption of reduction equivalents during maintenance of redox balance in anaerobic and aerobic metabolism. Anaerobic oxidative phosphorylation is discussed for the reduction of fumarate and double bonds in lipids.

energy in oxidative phosphorylation. During anaerobiosis, fumarate may be used as an electron acceptor instead of oxygen (e.g. Wilson \& Cascarano, 1970). Oxidative phosphorylation may also be involved during the reduction of double bonds in lipids (van den Thillart \& van Waarde, 1985). There is, however, no net production of protons by oxidative phosphorylation since protons are turned over by ATP independently of the pathways of carbon chains. This seems to be a general characteristic of oxidative phosphorylation, which depends on a $\mathrm{pH}$ gradient created by proton transport. Only during substrate-level phosphorylation (Fig. 5) may ATP become involved in the proton release from carboxyl groups. This happens in the glycolytic pathway and during release of carboxyl groups from CoA esters, e.g. from propionyl-CoA, succinyl-CoA or acetyl-CoA. The carboxylation of phosphoenolpyruvate is a reaction that is very likely to involve proton release via ATP (after transphosphorylation from GTP or ITP). It is interesting to note that all substratelevel phosphorylations observed in animal tissues are linked to proton production 
from the substrate involved. In a mechanism analogous to that of oxidative phosphorylation (see Kagawa, 1985), the major part of the energy that drives ATP synthesis could therefore originate from the proton which tends to be released from

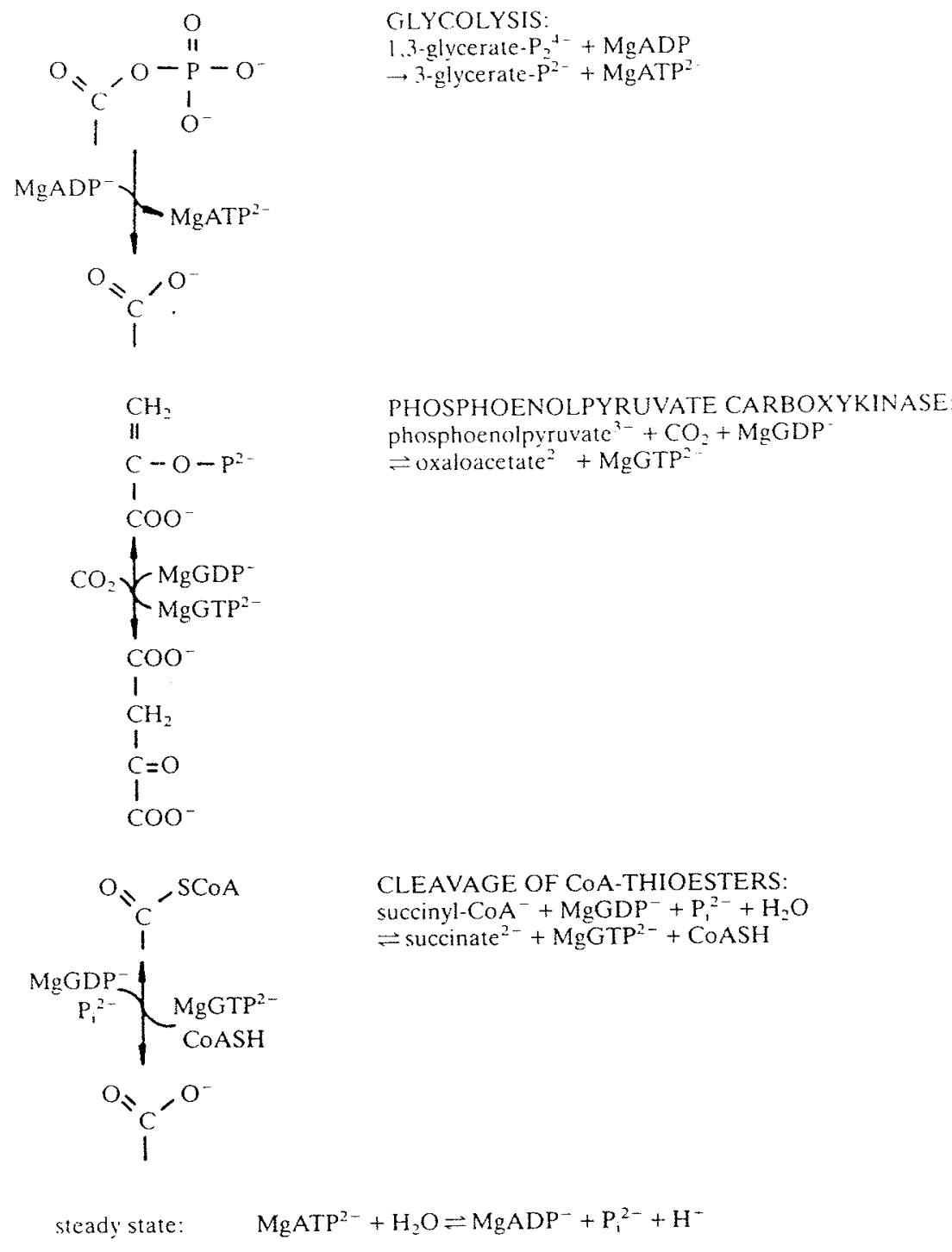

Substrate level phosphorylation: turnover of protons via ATP linked to (transient ot net)

proton release from the pathway.

Fig. 5. Substrate-level phosphorylation in the catabolism of carbon chains. Analogous to oxidative phosphorylation, the mechanism may be such that the proton to be released from the acidic (carboxyl) group (see text) drives ATP synthesis. Examples are shown which lead to net proton formation in anaerabic metabolism. 
the acidic group. ATP release from the A'TPase is assumed to be the energy-requiring step in ATP synthesis during substrate-level and oxidative phosphorylations (Kagawa, 1985). Proton release from the acidic group could drive the ATP release. This would mean, however, that the pathway proton is then not consumed by ATP synthesis, but its release may nevertheless be involved in ATP formation. The stoichiometry discussed here is the same in both cases. (During ATP formation involving phosphoenolpyruvate and pyruvate kinase the proton originates from the enol form of pyruvate, the enolate anion enolpyruvate ${ }^{2-}$ being the immediate product of the reaction. During the energy-yielding, biotin-dependent decarboxylation of methyl-malonyl-CoA, which occurs during propionate formation, carbonic acid may deliver the proton needed for ATP synthesis. The latter mechanism would also be valid for the pyruvate-carboxylase-dependent decarboxylation of oxaloacetate that is assumed to occur in anoxic goldfish, see van den Thillart \& van Waarde, 1985.)

A comparison of the events in the cytoplasm and the mitochondria reveals that, during aerobic and anaerobic breakdown of carbohydrates, net proton production occurs only in the cytosol. In the aerobic citric acid cycle, $\Delta \mathrm{H}^{-}$is actually -1 :

$$
\text { Pyruvate }^{-}+\mathrm{H}^{+} \rightarrow 3 \mathrm{CO}_{2}+6 \mathrm{H} \text {. }
$$

This means that metabolism supports the generation of a $\mathrm{pH}$ gradient between the mitochondria and the cytosol, which implies at least that pyruvate and $\mathrm{H}^{+}$ cotransport into the mitochondrion (LaNoue \& Schoolwerth, 1979) is possible without reduction of the ATP yield in oxidative phosphorylation. During anaerobiosis, the support by metabolism for build-up of a proton gradient across the inner mitochondrial membrane may be even more pronounced when dicarboxylic acid anions enter the mitochondrion and are decarboxylated (see Fig. 3).

Generally, the utilization of 'aerobic' reactions during mitochondrial anaerobiosis diminishes the amount of protons generated in catabolism compared with the amount of ATP formed (Table 1) and thereby contributes to long-term survival of the respective tissue under hypoxia. The decrease of the $\mathrm{H}^{+} / A T P$ ratio (Gnaiger, 1980) is even more distinct when amino or dicarbonic acids take part as anaerobic substrates. Cytosolic ATP production will become involved when the amino group of, for example, aspartate or glutamate is transferred to pyruvate, vielding alanine (Figs 3, 6). This proton production, however, is compensated for when propionate or acetate are formed from aspartate by decarboxylation, as described for marine facultatively anaerobic invertebrates (Table 1; Fig. 3). Formation of succinate from glutamate, aspartate or malate is neutral for the acid-base status. As a result, ATP generation is possible without increasing the proton load of the tissue. Perhaps the beneficial effect observed during treatment of the ischaemic heart with glutamic acid (Bittl \& Shine, 1983) may, in part, be caused by the decrease of the $\mathrm{H}^{+} /$ATP ratio during anaerobiosis; the ratio is 1 during lactate formation (from glucose), 0.5 during alanine production stoichiometrically linked to succinate production from glutamate or aspartate, and zero during formation of succinate from $\alpha$-ketoglutarate. 


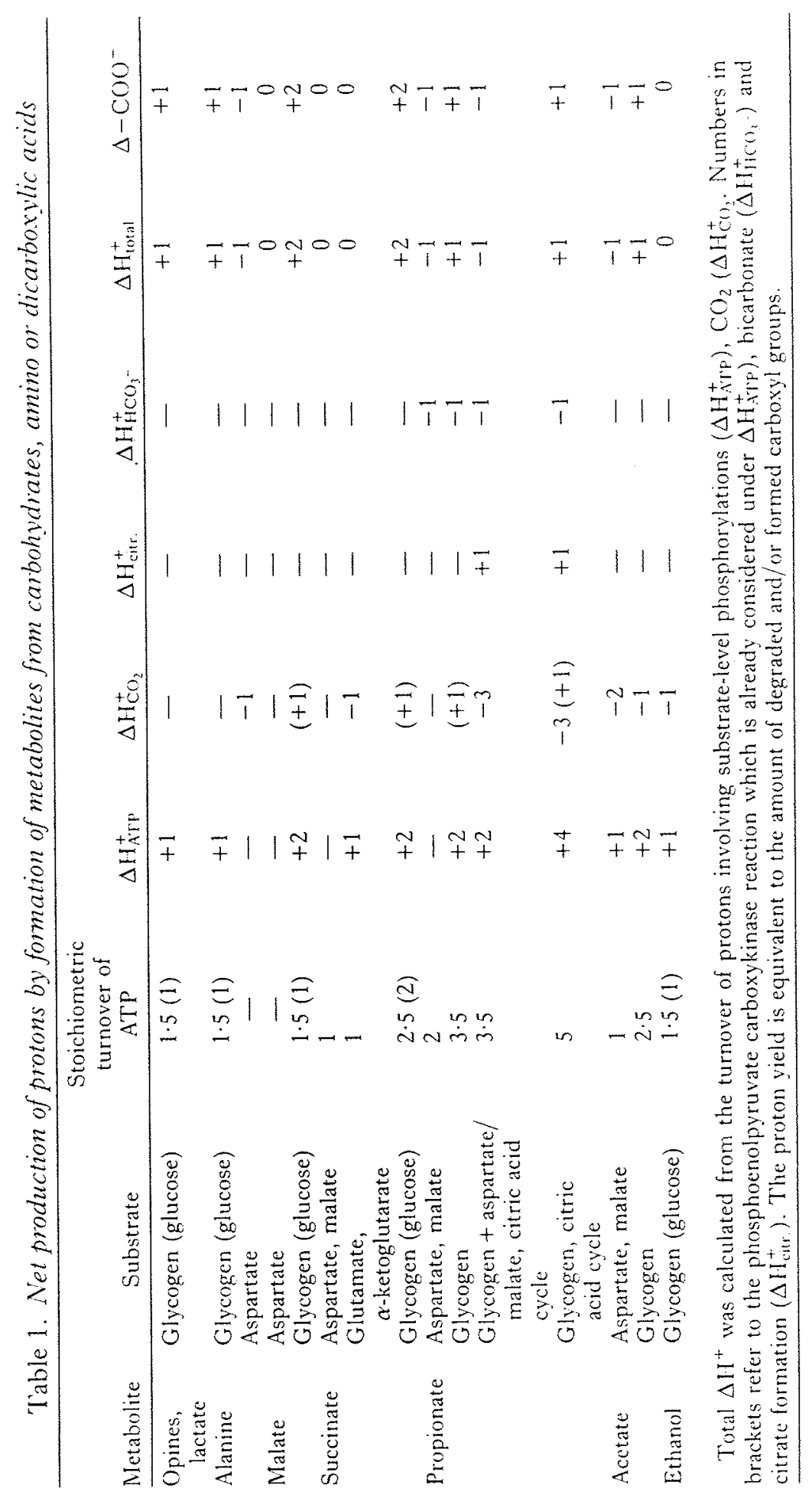




\section{AMMONIUM METABOLISM}

Another point that is often overlooked in analysing the proton yield of anaerobic metabolism is the role that amino groups and ammonium play (Fig. 6). During anaerobiosis in marine invertebrates, pyruvate is formed to yield alanine by taking over the amino groups from aspartate or glutamate, the carbon skeleton being converted into malate, succinate and propionate (Felbeck, 1980). Several authors, however, have reported that alanine formation is greater than aspartate degradation (e.g. Pörtner et al. 1986a). In Limulus polyphemus, aspartate degradation contributes negligibly to alanine formation (Carlson \& Gäde, 1983). This means either a degradation of protein and a net accumulation of amino groups in alanine after transamination, or a reductive amination of $\alpha$-ketoglutarate or pyruvate, finally also yielding alanine.

Protons are consumed during protein or amino acid catabolism (Atkinson \& Camien, 1982; Fig. 6). Net proton consumption would be indicated by the net accumulation of amino groups (in alanine) or by the accumulation of ammonium ions. The question arises as to where other ammonium ions accumulated, or possibly fixed by reductive amination, come from and what this means for the proton rield of metabolism (Fig. 6)? Deamidation of glutamine, deamination of AMP and adenosine, the arginase reaction and subsequent hydrolysis of urea, as well as the oxidation of amino acids without oxygen, are anaerobic means of ammonium production, whereas residual aerobic metabolism and uric acid catabolism would require oxygen for ammoniagenesis. Excluding glutamine deamidation, ammoniagenesis is always linked to proton binding, possibly because ammonia itself binds a proton (e.g. during AMP deamination, see Table 2) or because bicarbonate is formed during release of the ammonium ion (e.g. uricolysis and the arginase reaction, including subsequent ureolysis). $\mathrm{H}^{+}$could also be bound during oxidative decarboxylation, yielding $\mathrm{CO}_{2}$ (amino acid oxidation). When ammonia leaves the organism, this may predominantly occur in the form of non-ionic diffusion, as described for fish (Cameron \& Heisler, 1983). The proton remains in the organism and this eliminates the base load originating, for example, from protein catabolism. If ammonium disposal occurs by ionic transport, the associated base equivalents remain, a process that may be advantageous in reducing the metabolic proton load during anaerobiosis or during the first phase of recovery from anaerobiosis. If alanine is accumulated for disposal of ammonium or amino groups, glycolytic ATP can be produced without net acidification and the requirement of redox balance is also fulfilled. This may be one explanation for why alanine is found to be formed during anaerobiosis in marine invertebrates and also during muscular activity, for example, in vertebrate muscle (see Snell, 1980).

\section{NON-STEADY STATE}

The assumption of steady-state conditions in terms of constant $\mathrm{CO}_{2}$, bicarbonate and adenylate concentrations and stable redox status has helped to demonstrate that the balance of carboxyl groups determines the non-volatile proton load caused by 
Proton balance of $\mathrm{NH}_{4}{ }^{+}$metabolism during hypoxia

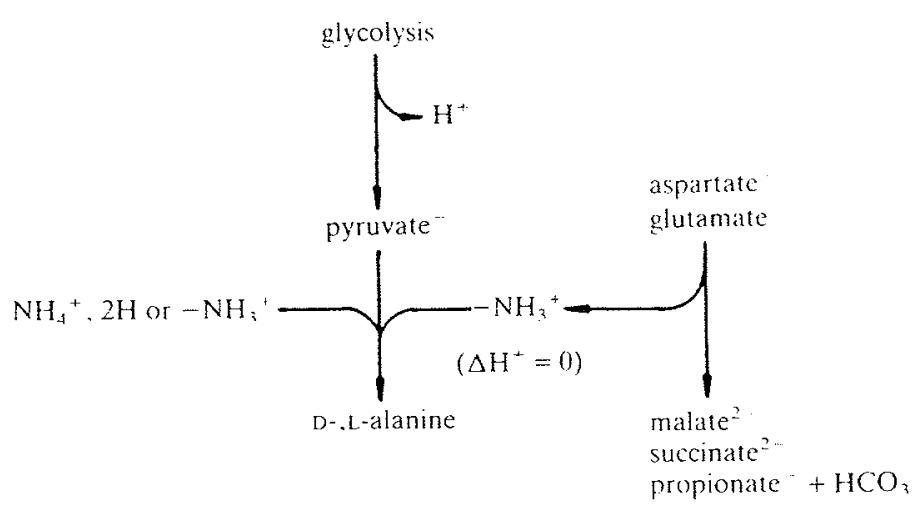

Origin of $\mathrm{NH}_{4}^{+}$:

(a) residual aerobic metabolism:

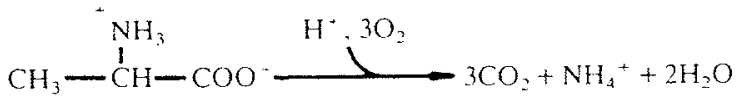

(b) uric acid?:

urate ${ }^{-1}\left(\mathrm{C}_{5} \mathrm{~N}_{4} \mathrm{H}_{3} \mathrm{O}_{3}{ }^{-}\right)+0 \cdot 5 \mathrm{O}_{2}+3 \mathrm{H}_{2} \mathrm{O}$

glyoxylate ${ }^{-}+2$ urea $+\mathrm{CO}_{2}$

$2 \mathrm{H}^{+}, 4 \mathrm{H}_{2} \mathrm{O}$

glyoxylate ${ }^{+}+4 \mathrm{NH}_{4}{ }^{+}+2 \mathrm{HCO}_{3}^{-}+\mathrm{CO}_{2}$

(c) glutamine:

glutamine $+\mathrm{H}_{2} \mathrm{O} \longrightarrow$ glutamate ${ }^{-}+\mathrm{NH}_{4}{ }^{+}$

(d) AMP, adenosine:

$\mathrm{AMP}+\mathrm{H}^{+}+\mathrm{H}_{2} \mathrm{O} \longrightarrow \mathrm{NH}_{4}{ }^{+}+\mathrm{IMP}$

adenosine $+\mathrm{H}^{+}+\mathrm{H}_{2} \mathrm{O} \longrightarrow \mathrm{NH}_{4}{ }^{+}+$inosine

(e) arginine?

arginine ${ }^{+}+3 \mathrm{H}_{2} \mathrm{O}+\mathrm{H}^{+} \longrightarrow 2 \mathrm{NH}_{4}^{+}+\mathrm{HCO}_{3}{ }^{-}+$ornithine ${ }^{+}$

(f) anaerobic oxidation of amino acids?

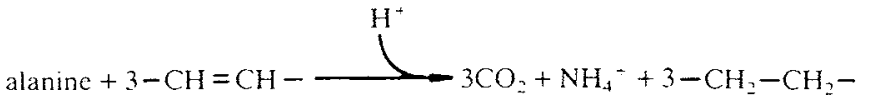

Fig. 6. Proton balance during catabolism of nitrogen-containing substances towards ammonium. Accumulation of ammonium in all cases but one represents concomitant proton consumption. This stoichiometry is the same when amino groups in alanine originate from reductive amination or transamination (except during formation of malate or succinate from aspartate or glutamate) or when accumulated ammonium is released to the environment by means of ionic transport (see text). 
metabolism. Changes in the concentrations of bicarbonate and $\mathrm{CO}_{2}$ directly reflect changes in $\mathrm{pH}$ according to the Henderson-Hasselbalch equation. The $\mathrm{CO}_{2} /$ $\mathrm{HCO}_{3}^{-}$system is influenced not only by metabolic proton, bicarbonate or $\mathrm{CO}_{2}$ formation but also by respiration, non-bicarbonate buffering and ion transfer. These interrelationships are described by acid-base physiology. Using the appropriate methodology, changes in intra- and extracellular $\mathrm{CO}_{2}$ and bicarbonate concentrations can be monitored and the influence of respiration and buffering, as well as the influence of metabolic proton generation and ion transport, can be quantitatively analysed (Heisler, 1986). This paper, therefore, focuses on the generation or consumption of non-rolatile acidic groups, the quantification of which requires the methodology of metabolite analysis (see Pörtner et al. 1986a,b; Pörtner, 1987 as examples of the analysis of quantitative correlations between metabolic and acid-base events).

Maintenance of the concentrations of the adenylates has rarely been described for anaerobic tissues (Pörtner et al. 1984c). A decrease in the ATP content linked to the increase of ADP and AMP concentrations, as well as the subsequent degradation of AMP, is more likely to occur (Atkinson, 1977). These processes have their specific influence on the acid-base status and may be treated as being independent of the pathway, although they cause an increased ATP synthesis by metabolism and by transphosphorylation from the phosphagen.

The physicochemical properties of the adenylates in vivo are influenced by the degree of complexation with $\mathrm{Mg}^{2+}$. The essential point to note is that the binding of $\mathrm{Mg}^{2+}$ lowers the $\mathrm{H}^{+}$dissociation constants of the phosphate groups. It is obvious, however, that the affinity for $\mathrm{Mg}^{2+}$ decreases in the order $\mathrm{ATP}^{4-}>\mathrm{ADP}^{3-}>$ $\mathrm{AMP}^{2-} \approx \mathrm{P}_{1}{ }^{2-} \approx I \mathrm{MP}^{2-}$ (Pörtner et al. 1984b). The amount of protons released during hydrolysis of $\mathrm{MgATP}^{2-}$ is determined by (a) the $\mathrm{pK}^{\prime}$ shift of the released inorganic phosphate, (b) cell $\mathrm{pH}$ and (c) a possible $\mathrm{pK}^{\prime}$ shift of the remaining phosphate groups in $\mathrm{ADP}^{3-}$ caused by the lower affinity for $\mathrm{Mg}^{2+}$. If the recent observation of a low free $\mathrm{Mg}^{2+}$ concentration ( $<1 \mathrm{mmoll}^{-1}$, Gupta, Gupta, Yushok \& Rose, 1983; Maughan, 1983) is generally valid for all tissues, this means that the degree of proton release by cleavage of $\mathrm{MgATP}^{2-}$ in muscle tissue may have been overestimated in other studies. The proton vield by hydrolysis of $\mathrm{MgATP}^{2-}$ is markedly reduced by the dissociation of $\mathrm{Mg}^{2+}$ from $\mathrm{MgADP}$ and by the conversion of ADP to IMP, since the formation of IMP from AMP means proton consumption resulting from the release of ammonia (Pörtner et al. 1984b). This is valid even when the protonated ammonia is fixed by the glutamate dehydrogenase reaction. A correlation seems to exist between the development of progressive acidosis and ongoing AMP deamination, especially in tissues exhibiting inorganic phosphate accumulation from the depletion of the phosphagen (Dudley \& Terjung, 1985). Accumulated ammonia does not leave the muscle tissue (Terjung, Dudley \& Mever, 1985), a fact which supports the assumption of its proton buffer function during AMP deamination. If AMP hydrolysis and deamination of adenosine prevail, as reported for mammalian heart muscle (Jennings \& Steenbergen, 1985), proton consumption is even more distinct, because the $5^{\prime}$-nucleotidase reaction is involved. 
Table 2. Hudrolysis on fomation of ATP at 0.5 mmol $\mathrm{Mg}^{2+} \mathrm{l}^{-1}$ and $\mathrm{pH} 7 \cdot 3$ or $6 \cdot 9$; constants adopted from Portne', Heisler Grieshaber (1984b) and Gupta, Gupta, lushok $=$ Rose (1983)

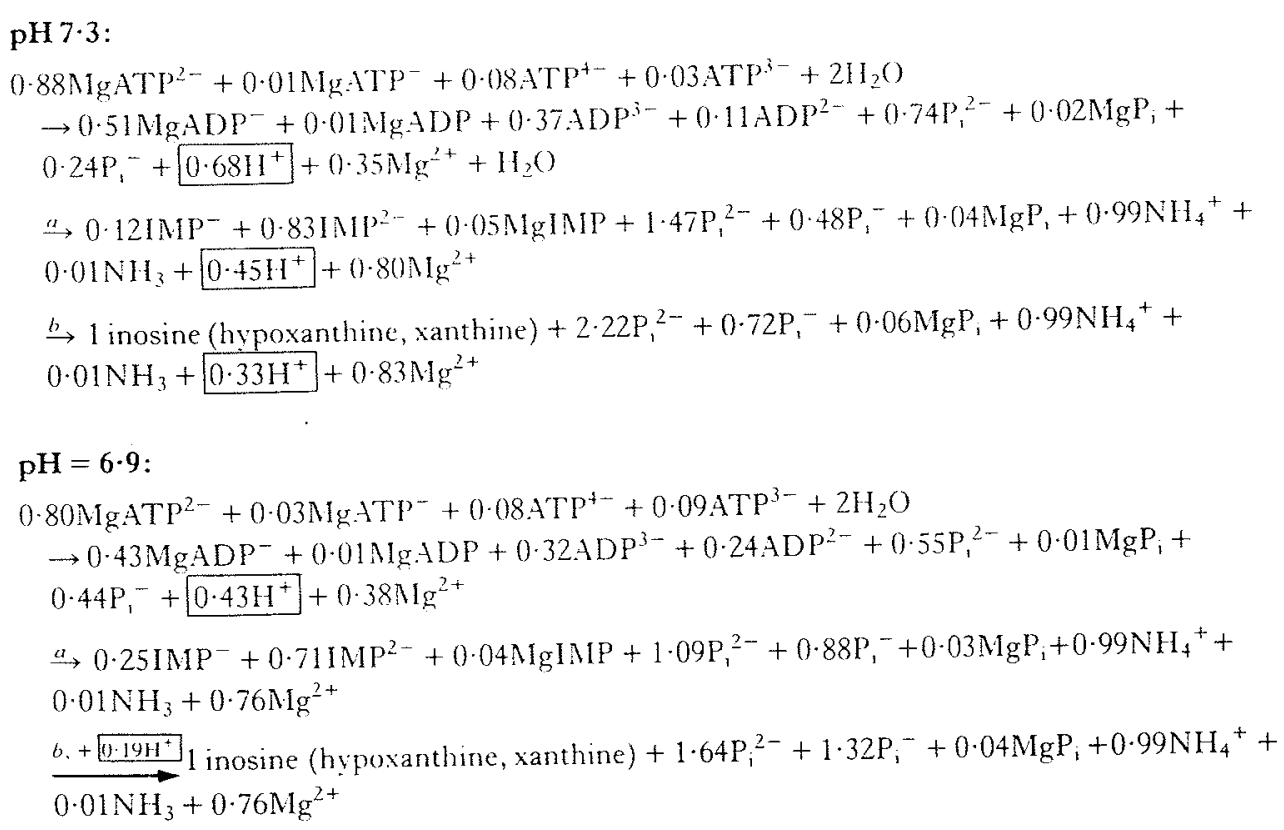

Metabolism of ANP may include direct deamination ( $a$, Atkinson, 1977) or formation and subsequent deamination of adenosine as reported for mammalian heart muscle $(b$, Jennings \& Steenbergen, 1985).

Moreover, intracellular $\mathrm{pH}$ falls during anaerobic muscle performance and thereby further reduces the amount of protons released. In conclusion, the metabolism of the adenylates tends to minimize the proton load of the cell that is caused by net hydrolysis of $\mathrm{MgATP}^{2-}$ (Table 2), an observation that has to be taken into account whenever a net decrease in the sum of the adenylate concentrations (ATP, ADP, AMP) occurs.

\section{CONCLUSIONS}

Proton balance of (anaerobic) metabolism is most easily assessed by comparing the physicochemical properties of all the substrates and products of a reaction chain: in the catabolism of carbon chains, the proton yield is determined by the net formation or degradation of carboxyl groups (Table 1). Anaerobic metabolism, therefore, is not necessarily linked to proton accumulation, if amino and other organic acids are utilized as substrates instead of carbohydrates. When net concentration changes in organic phosphates occur, their specific influence on the acid-base status is observed. The degree of influence depends upon the $\mathrm{pK}^{\prime}$ shift of the phosphate group between the bound and free state. Occasionally, such $\mathrm{pK}^{\prime}$ shifts must also be 
considered in the metabolism of amino groups (e.g. AMP, adenosine deamination). The analysis reveals that proton release from the substrate may play an important role in substrate-level phosphorylation.

During anaerobiosis, as compared to aerobic control values, the efficiency of ionic $\mathrm{pH}$ regulation may be reduced and $\mathrm{pH}$ changes may occur (Pörtner et al. 1984a; Pörtner, 1987). pH regulation during anaerobiosis, however, is also a minimization of proton accumulation by metabolism. 'This implies that protons are consumed during phosphagen depletion and that inorganic phosphate accumulates as an additional buffer substance. During long-term adaptations to hypoxia, the stoichiometric amount of protons generated per mol of ATP turned over is reduced from unity to a lower value. In some cases, end-products, such as acetate or propionate, may leave the animal in protonated form, thereby reducing the metabolic proton load. These mechanisms, supported by the reduction of the anaerobic metabolic rate, ensure low rates of anaerobic proton accumulation and long-term survival under hypoxia.

The author wishes to thank M. Grieshaber, S. Morris, J. Piiper, D. Toews and R. Boutilier for reading and commenting on different versions of the manuscript. Supported by DFG Po 278/1-1.

\section{REFERENCES}

Atkinson, D. E. (1977). Cellular Energy Metabolism and its Regulation. New York: Academic Press.

AtKinson, D. E. \& CAMIEN, M. N. (1982). The role of urea synthesis in the removal of metabolic bicarbonate and the regulation of blood pH. Cur. Topics cell. Reg. 21, 261-302.

BrmL, J. A. \& SHINE, K. J. (1983). Protection of ischemic rabbit myocardium by glutamic acid. Am. F. Physiol. 245, H406-H412.

Busa, W. B. \& Nuccitellt, R. (1984). Metabolic regulation via intracellular pH. Am. \%. Physiol. 246, R409-R438.

Cameron, J. N. \& Heisler, N. (1983). Studies of ammonia in the rainbow trout: physicochemical parameters, acid-base behaviour and respiratory clearance. $\mathcal{F}$. exp. Biol. 105, 10 $\bar{\tau}-125$.

CARLSON, K. H. \& GÄDE, G. (1983). L-alanine is an important end product during anoxia in the horseshoe crab Limulus polyphemus. Verh. dt. zool. Ces. 1983, 274.

Chih, C. P. \& Ellington, W. R. (1985). Metabolic correlates of intracellular pH change during rapid contractile activity in a molluscan muscle. F. exp. Zool. 236, 27-34.

Cooper, T. G., TCHen, T. T., Wood, H. G. \& Benedict, C. R. (1968). The carboxylation of phosphoenolpyruvate and pyruvate. I. The active species of " $\mathrm{CO}_{2}$ " utilized by phosphoenolpyruvate carboxykinase, carboxytransphosphorylase, and pyruvate carboxylase. 7. biol. Chem. 243, 3857-3863.

Dixon, H. \& WEBB, E. C. (1979). Enzymes. London: Longman Group Ltd.

Dudley, G. A. \& TERJUNG, R. L. (1985). Influence of acidosis on AMIP deaminase activity in contracting fast-twitch muscle. Am. 7. Physiol. 248, C43-C50.

ERECINSKA, M. \& WiLSON, D. F. (1982). Regulation of cellular energy metabolism. 7 . Membr. Birl. $70,1-14$

FELBECK, H. (1980). Investigations on the role of the amino acids in anaerobic metabolism of the lugworm Arenicola marina. F. comp. Physiol. 137, 183-192.

FREMINET, A. (1981). Carbohydrate and amino acid metabolism during acute hypoxia in rats: blood and heart metabolites. Comp. Biochem. Phisiol. 70B, 427-433.

GÄDE, G. \& GRIESHABER, M. K. (1986). Pyruvate reductases catalyze the formation of lactate and opines in anaerobic invertebrates. Comp. Biochent. Physiol. 83B, 255-272. 
Gevers, W. (1977). Generation of protons by metabolic processes in heart cells. F. molec. cell. Cardiol. 9, $867-874$.

GNajger, E. (1980). Das kalorische Aquivalent des ATP-L'msatzes im aeroben und anoxischen Metabolismus. Themochim. Acta 40, 195-223.

Gupta, R. K., Gupta, P., Yushok, W. D. \& Rose, Z. B. (1983). Measurement of the dissociation constant of MgATP at physiological nucleotide levels by a combination of ${ }^{31}$ P NMR and optical absorbance spectroscopy. Biochem. biophys. Res. Commun. 117, 210-216.

HANSL, N. \& WaYgoOd, E. R. (1952). Kinetic studies of plant decarboxylases and carbonic anhydrase. (an. \%. Bot. 30, 306-317.

Heisler, N. (ed.) (1986). Acid-Base Regulation in Animals. Amsterdam: Elsevier Science Publishers B.Y.

Hochachka, P. W. \& Mommsen, T. P. (1983). Protons and anaerobiusis Science 219, 1391-1397.

HochachKa, P. W., OWEN, T. G., Alles, J. F. \& Whtrow, G. C. (1975). Multiple end products of anaerobiosis in diving vertebrates. (omp. Biochem. Physiol. 50B, 17-22.

JACKSON, D. C. (1986). Acid-base regulation of reptiles. In Acid-Base Regulation in Animals (ed. N. Heisler), pp. 235-263. Amsterdam: Elsevier Science Publishers B.V.

Jennings, R. B. \&.SteEnbergen, C. JR (1985). Nucleotide metabolism and cellular damage in myocardial ischemia. A. Rez. Physiol. 47, 727-749.

Kagawa, Y. (1985). Proton motive ATP synthesis. In Bigenergetics (ed. L. Enster), pp. 149-186. Amsterdam: Elsevier Science Publishers B.T.

Kaziro, Y., Hass, L. F., Boyer, P. D. \& OChoA, S. (1962). Mechanism of the propionyl carboxylase reaction. II. Isotopic exchange and tracer experiments. \%. biol. (hem. 237, $1460-1+1468$

LaNoue, K. F. \& Schoolwerth, A. C. (1979). Metabolite transport in mitochondria. A. Rez: Biochem. 48, 871-922.

Maughan, D. (1983). Diffusible magnesium in frog skeletal muscle cells. Biophy's. F. 43, 75-80.

Meyerhof, O. \& LohmanN, K. (1928). Über die natürlichen Guanidinophosphorsäuren (Phosphagene) in der quergestreiften Muskulatur. II. Die physikalisch-chemischen Eigenschaften der Guanidinophosphorsäuren. Biochem. Z. 196, 49-72.

PÖRTNER, H.-O. (1982). Biochemische und physiologische Anpassungen an das Leben im marinen Sediment: Untersuchungen am Spritzwurm Sipunculus muctus L. Dissertation, Universität Düsseldorf.

PorTNer, H.-O. (1987). Anaerobic metabolism and changes in the acid-base status: quantitative interrelationships and $\mathrm{pH}$ regulation in the marine worm Sipunculus mudus. F. exp. Biol. 131, $89-105$.

Pörtner, H.-O., Grieshaber, M. K. \& Heisler, N. (1984a). Anaerobiosis and acid-base status in marine invertebrates: effect of environmental hypoxia on extracellular and intracellular $\mathrm{pH}$ in Sipunculus mudus L. F. comp. Physiol. 155B, 13-20.

Pórtner, H.-O., Heisler, N. \& Grieshaber, M. K. (1984b). Anaerobiosis and acid-base status in marine invertebrates: a theoretical analysis of proton generation by anaerobic metabolism. 7. comp. Phvsiol. 155B, 1-12.

Pörtner, H.-O., Kreutzer, U., Siegmund, B., Heisler, N. \& Grieshaber, M. K. (1984c). Metabolic adaptation of the intertidal worm Sipunculus mudus to functional and environmental hypoxia. Mar. Biol. 79, 237-247.

Pörtner, H.-O., Vogeler, S. \& Grieshaber, M. K. (1986a). Recovery from anaerobiosis in the intertidal worm Sipunculus nudus. I. Restoration of aerobic, steady-state energy metabolism. 7. exp. Biol. 122, 37-50.

Pórtner, H.-O., Vogeler, S. \& Grieshaber, M. K. (1986b). Recovery from anaerobiosis in the intertidal worm Sipunculus nudus. II. Gas exchange and changes in the intra- and extracellular acid-base status. F. exp. Biol. 122, 51-64.

SAnborn, T., Gavin, W., Berkowitz, S., Perllle, T. \& Lesch, M. (1979). Augmented conversion of aspartate and glutamate to succinate during anoxia in rabbit heart. Am. F. Physiol. 237, $11535-\mathrm{H} 541$.

SCHOTTLER, L. (1980). Der Energiestoffwechsel bei biotopbedingter Anaerobiose: Untersuchungen an Anneliden. Verh. dt. sool. Ge's. 1980, 228-240. 
Schulz, T. K. F. van Duin, M. \& 7andee, D. 1. (1983). Propionyl-CoA carboxylase from the sea mussel Mytilus edulis L.: Some propertics and its role in the anaerobic energ: metabolism. Holec. Phisiol. 19, 215-230.

SNeli, K. (1980). Muscle alanine sunthesis and hepatic gluconeogenesis. Biochem. Sor. Trans. 8, $205-213$.

SOBEr, H. A. (ed.) (1973). Handbock of Biochemistry. Selected Data for Molecular Biology. Cleveland, Ohio: CRC Press.

TAEGTMEYER, H. (1978). Netabolic responses to cardiac hypoxia. Increased production of succinate by rabbit papillary muscle. ('ivulation Res. 43, 808-815.

Terjung, R. L., Dudery, G. A. \& Meyer, R. A. (1985). Metabolic and circulatory limits to muscular performance at the organ level. \% exp. Biol. 115, 307-318.

van deN THILlart, G. \& van WaARde, A. (1985). Teleosts in hypoxia: aspects of anaerobic metabolism. Holec. Physiol. 8, 393-409.

VAN ThoAi, N. \& Roche, J. (1964). Diversity of phosphagens. In Taxonomic Biochemistry and Serology (ed. C. A. Leone), pp. 348-362. New York: The Ronald Press Company.

Wilps, H. \& ZEBE, E. (1976). The end products of anaerobic carbohydrate metabolism in the larvae of Chronomus thummi thummi. F. comp. Physiol. 112, 263-272.

Wilson, M. A. \& Cascarano, J. (1970). The energy-yielding oxidation of NADH by fumarate in submitochondrial particles of rat tissues. Biochim. biophys. Acta 216, 54-62.

ZiLvA, J. F. (1978). The origin of the acidosis in hyperlactataemia. Am clin. Biochem. 15, 40-43. 